\title{
Spelling and dialect: Comparisons between speakers of African American vernacular English and White speakers
}

\author{
REBECCA TREIMAN \\ Washington University, St. Louis, Missouri
}

\begin{abstract}
One characteristic of African American vernacular English (AAVE) is final obstruent devoicing, where the final consonant of a word like rigid is pronounced more like /t/ than $/ \mathrm{d} /$. To determine whether this dialect characteristicinfluences adults' spelling, African American and White college students spelled words such as rigid and ballot, pronounced by either a speaker of their own dialect or a speaker of the other dialect. African Americans, especially those who often devoiced final /d/, were more likely than Whites to confuse $d$ and $t$. Both African American and White spellers made more $d / t$ confusions when the words were spoken by an African American experimenter than by a White experimenter. Thus, the different phonological systems of AAVE and White speakers can cause them to make different types of spelling errors. Discussions of AAVE and literacy have focused on its syntax, but its phonology must also be considered.
\end{abstract}

Those who have investigated spelling and its development have concluded that, for children, spelling is largely an attempt to represent the sounds heard in words (e.g., Frith, 1985; Read, 1975; Treiman, 1993). The sound system of a language may differ from one dialect to another, and so it is not surprising that young children's spellings may differ in ways that reflect the phonological characteristics of their dialects (see, e.g., Read, 1986; Treiman, Goswami, Tincoff, \& Leevers, 1997). What is more surprising is that dialect appears to influence spelling even in adults (Treiman \& Barry, 2000). This result is surprising in light of what Pennington, Lefly, Van Orden, Bookman, and Smith (1987) called the phonological bypass hypothesis - the hypothesis that phonology is superseded by other strategies in the course of spelling and reading development. According to that hypothesis, skilled spellers rely on word-specific knowledge, familiar letter patterns, and morphology; they do not construct spellings of known words from the words' phonological forms (e.g., Burt \& Fury, 2000; Frith, 1985).

Dialect influences on adults' spelling were documented by Treiman and Barry (2000) in a study of British and American college students. That study focused on one salient difference between British English and American

This research was supported by NSF Grants SBR-9408456, SBR9807736, and BCS-0130763 and a grant from the College of Urban, Labor, and Metropolitan Affairs at Wayne State University. Thanks to Rigel Dawson, Lia Sotak, Kira Rodriguez, Bruce Weinberger, and Suzanne Bick for research assistance and to Brett Kessler for comments on a draft of the manuscript. Correspondence should be addressed to R. Treiman, Department of Psychology, Washington University, One Brookings Drive, St. Louis, MO 63130-4899(e-mail: rtreiman@wustl. edu).
English - the fact that / / may not occur after a vowel within a syllable in most varieties of spoken British English but may occur in this position in most varieties of spoken American English. ${ }^{1}$ For example, speakers in England and Wales typically pronounce horde without an $/$, whereas those in the United States typically include it. This difference between the two dialects was reflected in spelling. The percentage of misspellings of words like horde that did not include an $r$ was almost three times larger among British college students than among Americans.

The present work goes beyond that of Treiman and Barry (2000) by addressing three issues. The first issue concerns generality: Are dialect-related spelling effects found for other pairs of dialects and for phonemes other than $/ /$ ? The present study examined two varieties of English in wide use in the United States - that of African American vernacular English (AAVE) and that of White speakers from the Northern states. There has been much discussion of AAVE, sometimes called Ebonics, and how it may affect the acquisition of literacy. That discussion has usually focused on the syntax of AAVE. For example, some have suggested that primers for AAVE-speaking children use AAVE sentence structure to make the books easier for the children to read (see Labov, 1995). Phonology has not been a major focus of discussion, partly because of previous work reporting few spelling errors related to AAVE phonology beyond the early school grades (Groff, 1978). The present study returned to phonology in order to ask whether phonological differences between African American and White speakers lead to different types of spelling errors in adults.

The phonological characteristic of AAVE of interest here was the devoicing of final obstruents (e.g., Bailey \& 
Thomas, 1998). In AAVE, the final /d/ of a word like ballad may be pronounced more like a voiceless / $t$ / than like a voiced /d/, causing ballad and ballot to end similarly. Linguists have not studied this process in detail, but it is quite noticeable in Detroit, the locus of the present study. Speakers who typically drop the $/ /$ in words like mother may include it when attempting to "talk White," but Detroit speakers of AAVE whose speech approximates that of Whites in most respects often devoice final obstruents. Their pronunciation of the final consonant of good in Have a good day may be one of the few speech cues to their background.

A second issue addressed by the present study concerned the nature of dialect-related spelling effects. When phonemes merge in a particular dialect, a speller may symbolize the resulting sound segment with the letter(s) most often associated with that segment, regardless of the segment's position. This seems to occur when U.S. children in the early elementary grades spell the intervocalic flaps of words such as lady and city. Children often use $d$ when $t$ is appropriate (e.g., sidy for city); they are less likely to make the reverse error (Treiman, Cassar, \& Zukowski, 1994). This pattern makes sense, given that flaps are similar to /d/. When children do not know the conventional spelling of the flap in a particular word, they apparently consider how /d/ is spelled in other words that they know. This phoneme is spelled as $d$ in most positions of words, even though it is often $t$ between vowels. Children's many $d$ errors suggest that they take little account of position in choosing spellings for phonemes. Post hoc analyses reported by Treiman and Barry (2000) point to a different pattern of results among U.S. college students. College students' errors on flaps appear to go in both directions - $t$ when $d$ is appropriate (e.g., autoble for audible) and $d$ when $t$ is appropriate (e.g., loider for loiter). This pattern suggests that adults restrict their purview to other words that contain flaps, a narrow context. Knowing that flaps are sometimes spelled as $d$ and sometimes as $t$, adults make errors in both directions.

For speakers of AAVE, the final consonants of words such as ballot and rigid merge to yield a segment that is more similar to /t/ than /d/. If spellers consider all instances of / $t /$ when deciding how to spell this segment, then errors such as rigit for rigid should greatly outnumber errors such as ballod for ballot. This is because $/ \mathrm{t} /$ is spelled as $t$ in most contexts in English. If spellers consider known words that contain the segment in the same specific context, then they should make errors such as ballod for ballot as well as errors such as rigit for rigid. This is because the set of known words with the segment in the same context includes items such as salad as well as items such as rabbit. The findings of Treiman and Barry (2000), together with other evidence that adult spellers are sensitive to context (Treiman, Kessler, \& Bick, 2002), suggest that the African Americans in the present study would make errors in both directions.

A third issue addressed in the present study was whether dialect-related spelling effects reflect the pronunciations that spellers hear, their own pronunciations, or both. These factors were confounded in the study of Treiman and Barry (2000), where the speaker who dictated the words used the same variety of English as did the speller. In the present study, some African Americans heard the words from a White speaker and others heard them from a speaker of AAVE. Similarly, the Whites heard the words from either a White speaker or a speaker of AAVE.

\section{METHOD}

\section{Stimuli}

Forty words were selected; they are listed in the Appendix. Twenty of the words, such as rigid, had an unstressed final syllable ending with $/ \mathrm{d} /$. Ten of these words were more common (mean frequency of 178 according to Zeno, Ivenz, Millard, \& Duvvuri, 1995) and 10 were less common (mean frequency of 9). The other 20 words ended with an unstressed syllable with final /t/, as in ballot. Ten were more common (mean frequency of 128) and 10 were less common (mean frequency of 8). A sentence was written for each word, with the critical word the last word of the sentence.

\section{Procedure}

The participants were told that they would spell a series of words, some of which could be rather difficult. For each word, the participants first rated its familiarity on a 7-point scale. A rating of 7 meant that the word was familiar to them and they knew its meaning well. A rating of 4 meant that they recognized it as a word but did not know its meaning. A rating of 1 meant that the word was totally unknown to them. After asking the participant to rate the word, the experimenter used it in the sentence, said the word again, and asked the participant to spell the word. When this phase of the experiment was completed, the experimenter said each critical word and sentence again and asked the participant to pronounce the word. The participant's pronunciations were taped. Finally, participants were asked a series of questions about their backgrounds.

\section{Participants}

The participants were students at Wayne State University in Detroit; all native speakers of English. Selection of participants benefited from the fact that the Detroit area is the most racially segregated metropolitan area in the U.S. (Trowbridge, 2002). African Americans and Whites typically live in different neighborhoods and attend different schools at the elementary through high school levels (Upton, 2002). One group of 46 students was chosen such that the students identified themselves as African American, Black, or Negro and had lived for more than two thirds of their lives in the city of Detroit, which has over $80 \%$ Black residents (Trowbridge, 2002). On average, these African American students had lived $96 \%$ of their lives in the city of Detroit. Typically, they were born in the city and had received all their schooling there. Twenty-two of these Black participants were tested by an African American experimenter, and 24 were tested by a White experimenter. The other group of participants identified themselves as Caucasian, White, or a member of a specific Caucasian group, and had lived within the Detroit city limits for less than one third of their lives. This group included 47 participants, 22 of whom were tested by an African American experimenter and 25 of whom were tested by a White experimenter. These students had generally grown up in the suburbs of Detroit, most of which are largely White. They continued to live in the suburbs while attending Wayne State University. On average, they had lived less than $2 \%$ of their lives within the city.

To verify that the African American and White students pronounced the test words differently, a White individual listened to the tapes and categorized each speaker's pronunciation of each final consonant as closer to /d/ or closer to /t/. Tapes were not available 
or not usable for 7 of the participants, so the analyses involving the taped pronunciations were based on 86 participants. A second White listener independently judged the pronunciations of 29 participants. The judges agreed on $93 \%$ of the classif ications. The mean percentage of /t/ judgments for final /d/ words was $40 \%$ for African American participants (range 0-95\%) and less than $1 \%$ for Whites (range $0-15 \%$ ). The effect of group was significant in an analysis of variance (ANOVA) using the factors of participant group (African American vs. White) and experimenter (African American vs. White) $[F(1,82)=104.95, p<.001]$. No other effects were signif icant. These results confirm that devoicing of final /d/ is a salient feature of African American Detroiters' speech and that most of the present participants sometimes used this feature. Consistent with previous reports (e.g., Bailey \& Thomas, 1998), variability was observed within and across individuals in the use of AAVE features. The setting may also affect performance, with speakers probably less likely to devoice final /d/s in the relatively formal situation of an experiment than in more informal situations. Still, the large differences between the two groups in the laboratory setting attest to the differences in their speech.

The African American experimenter was from Detroit and, like most of the African American participants, tended to devoice final /d/s. There were three Caucasian experimenters, none of whom was observed to do this.

\section{RESULTS AND DISCUSSION}

The analyses for each participant were restricted to words that the participant rated as at least somewhat familiar (ratings of 5, 6, or 7). Some of the words were unknown to some of the participants, and the processes involved in spelling such items may differ from those involved in spelling known words. The number of participants who rated a word as at least somewhat familiar correlated significantly with the number of occurrences of the word in Zeno et al. (1995) $(r=.60, p<.001)$.

Of primary interest are voicing errors in spelling, those in which final $d$ and $t$ are interchanged. For final /d/ words, voicing errors were spellings that ended with $t$ (or $t$ followed by $e$, which is often silent in English). Examples of voicing errors are haggart for haggard, which contains no errors beyond the substitution of $t$ for $d$, and ransite for rancid, which includes a consonant substitution elsewhere in the word and the addition of a final $e$ as well as the voicing error. Misspellings that did not include a voicing error on the final consonant were classified as "other" errors. Examples for final /d/ words are tipid for tepid, arrid for arid, ridige for rigid, and haggered for haggard. For final /t/ words, voicing errors were spellings that ended with $d$ or $d e$, including those with no other incorrect letters, as in thicked for thicket, and those with additional errors, as in ballad for ballot. Sample errors on $/ t /$ words that did not include a voicing error on the final $/ \mathrm{t} /$ and that were placed in the category of "other" errors are granuite for granite and ballott for ballot.

Table 1 shows the mean numbers of voicing errors and "other" errors as a function of final consonant, participant group, and experimenter. Also shown are the mean number of spellings analyzed in each cell - that is, the number of words that were rated as 5 or higher in familiarity. A good deal of variability was observed, but voicing errors were more common for African American spellers than for White spellers. Also, voicing errors were more common when the experimenter was African American rather than White. These impressions were confirmed by ANOVAs using the factors of final consonant $(/ \mathrm{d} /, / \mathrm{t} /$ ), participant group (African American, White), experimenter (African American, White), and word frequency (higher, lower). ANOVAs were performed by subjects, in which the factors of participant group and experimenter were between-subjects factors and the other factors were within-subjects factors, and by items, in which participant group and experimenter were within subjects and the other factors were between subjects. There was a main effect of participant group in both ANOVAs $\left[F_{1}(1,89)=48.82, p<.001 ; F_{2}(1,36)=13.42, p=\right.$ $.001]$. The effect of experimenter was also significant $\left[F_{1}(1,89)=8.18, p=.005 ; F_{2}(1,36)=7.37, p=.01\right]$. No other effects were significant both by subjects and by items. When the participant and the experimenter were both African American, $11 \%$ of all spellings of words of at least moderate familiarity included a voicing error. The figure was somewhat lower, $8 \%$, when the speller was African American but the tester was White. For White spellers, voicing errors occurred $3 \%$ of the time when the tester was African American and less than 1\% of the time when the tester was White. There was a trend toward more voicing errors by African American participants for /d/ than for / $t /$ that, although significant by subjects $[t(45)=2.32, p=.025]$, was not significant by

Table 1

Mean Number of Errors of Various Types and Mean Number of Words Spelled as a Function of Final Consonant, Participant Group, and Experimenter for Words Rated by Participants as 5 or Higher in Familiarity, With Standard Deviations

\begin{tabular}{|c|c|c|c|c|c|c|c|c|c|c|c|c|c|}
\hline \multirow[b]{3}{*}{ Group } & \multirow[b]{3}{*}{ Experimenter } & \multicolumn{6}{|c|}{ Words With Final /d/ } & \multicolumn{6}{|c|}{ Words With Final /t/ } \\
\hline & & \multicolumn{2}{|c|}{$\begin{array}{l}\text { Voicing } \\
\text { Errors }\end{array}$} & \multicolumn{2}{|c|}{$\begin{array}{l}\text { "Other" } \\
\text { Errors }\end{array}$} & \multicolumn{2}{|c|}{$\begin{array}{c}\text { All } \\
\text { Spellings }\end{array}$} & \multicolumn{2}{|c|}{$\begin{array}{l}\text { Voicing } \\
\text { Errors }\end{array}$} & \multicolumn{2}{|c|}{$\begin{array}{l}\text { "Other" } \\
\text { Errors }\end{array}$} & \multicolumn{2}{|c|}{$\begin{array}{c}\text { All } \\
\text { Spellings }\end{array}$} \\
\hline & & $M$ & $S D$ & $M$ & $S D$ & $M$ & $S D$ & $M$ & $S D$ & $M$ & $S D$ & $M$ & $S D$ \\
\hline AA & AA & 1.73 & 1.28 & 2.73 & 2.45 & 13.09 & 4.06 & 1.09 & 1.15 & 3.14 & 2.38 & 11.50 & 3.19 \\
\hline AA & $\mathrm{W}$ & 1.17 & 1.37 & 2.54 & 2.08 & 13.00 & 2.93 & 0.70 & 0.95 & 3.50 & 2.47 & 11.63 & 2.39 \\
\hline $\mathrm{W}$ & AA & 0.23 & 0.43 & 2.50 & 2.15 & 14.68 & 3.70 & 0.55 & 0.86 & 3.55 & 2.11 & 13.36 & 3.54 \\
\hline
\end{tabular}

Note-AA, African American; W, White. 
items $[t(38)=.94, p=.35]$. Both $/ \mathrm{d} /$ and $/ \mathrm{t} /$ words varied a great deal in the extent to which they elicited voicing errors, and these errors were relatively common for some words that ended with $/ \mathrm{t} /$, as well as for some words that ended with /d/.

Analogous ANOVAs were performed on the number of misspellings that did not include voicing errors on the final consonant, or "other" errors. No effects were significant both by subjects and by items. This finding shows, importantly, that the two groups of participants did not differ reliably in their tendency to misspell parts of the words other than the final consonants. The group differences were restricted to the segment most affected by differences in dialect, the final consonant.

With respect to the first issue discussed in the introduction, that of generality, the findings show that dialectrelated effects on adults' spelling occur for pairs of dialects other than the one investigated by Treiman and Barry (2000) and for segments other than the ones examined there. The results indicate that adults do not totally bypass phonology when spelling known words, as some have suggested (e.g., Burt \& Fury, 2000; Frith, 1985). Contrary to the conclusions of Groff (1978), misspellings related to the phonology of AAVE occur not only in young children but also in adults.

The results also speak to a second issue that is important for theories of spelling - the nature of dialect-related spelling effects. The fact that African American adults' misspellings go in both directions-errors such as rivid for rivet as well as errors such as rigit for rigid-suggests that adults use context in a rather narrow and specific way. When deciding how to spell the final segment of a word like rivet, adults consider primarily other words that have this segment in the same position. This set includes words such as salad and valid, causing adults to produce misspellings such as rivid. If adults considered a broad range of words with /t/, including those with initial / $\mathrm{t} /$, then errors such as rigit for rigid would markedly outnumber errors such as rivid for rivet. There was a trend in this direction, but it was not significant by items.

Previous studies of dialect-related misspellings have not examined the relative importance of the dialect in which the speller pronounces the words and the dialect in which the words are heard. The results presented so far suggest that both affect adults' spelling but that the speller's own dialect is more influential than the tester's dialect. Supporting this conclusion, Whites who heard words pronounced by a speaker of AAVE were less likely to confuse $d$ and $t$ than were African Americans who heard the words pronounced by a White speaker. To further address these issues, separate regression analyses were carried out for the 86 African American and White participants for whom taped pronunciations were available. The dependent variable was the proportion of voicing errors on words of at least moderate familiarity relative to the total number of spellings of such words. The predictors were the experimenter's race and the participant's rate of final /d/ devoicing as assessed from the tapes. The results are shown in Table 2. For both African American and White participants, voicing errors were more common when the experimenter was African American rather than White, which is consistent with the results presented earlier. The new finding is that, for African American participants, the participant's own rate of final /d/ devoicing made a reliable additional contribution to the prediction of voicing errors. That is, those African Americans who showed a strong tendency to devoice final /d/ were most likely to confuse $d$ and $t$ in their spelling. Those who showed less use of this dialect feature tended to make fewer such misspellings. Final/d/ devoicing was quite uncommon in the speech of the White participants, as stated earlier, and it did not make a significant contribution to the regression for these participants. Thus, spellers are most likely to make voicing confusions if the distinction between final /d/ and /t/ is often neutralized in their own speech and if they hear the words from a speaker who shows this same characteristic. The misspellings are least common when the participant distinguishes between final /d/ and /t/ in his or her own speech and the tester does too.

Written English is not a perfect match to any current dialect. Nevertheless, the results suggest that even experienced spellers attempt to construct words' spellings from the words' phonological forms. They do not rely only on word-specific knowledge, morphology, or other sources of information, as the phonological bypass hypothesis predicts. Because adults make decisions about spelling in part on the basis of words' phonological forms, they have difficulty with sound segments that have more than one possible representation. The degree of ambiguity in the spelling of a segment may differ from one variety of English to another, resulting in dialect differences in spelling.

The results have implications for social issues as well as for the processes involved in spelling. African Americans in the United States lag behind other groups in literacy skills (National Center for Education Statistics, 2002).

Table 2

Results of Separate Regression Analyses for African American and White Participants Predicting Proportion of Voicing Errors on Moderately Familiar Words Relative to All Spellings of Such Words

\begin{tabular}{|c|c|c|c|c|}
\hline Group & $n$ & Variable & $\beta$ & $p$ \\
\hline \multirow[t]{2}{*}{ African American } & 41 & Experimenter race $(0=$ White, $1=$ African American $)$ & .449 & .002 \\
\hline & & Participant's proportion of $/ \mathrm{t} /$ pronunciations of final $/ \mathrm{d} /$ & .436 & .001 \\
\hline \multirow[t]{2}{*}{ White } & 45 & Experimenter race $(0=$ White, $1=$ African American $)$ & .350 & .018 \\
\hline & & Participant's proportion of $/ \mathrm{t} /$ pronunciations of final $/ \mathrm{d} /$ & .178 & .217 \\
\hline
\end{tabular}

Note- $R^{2}=.35$ for African American participants, $p<.001 ; R^{2}=.17$ for White participants, $p=.020$. 
AAVE, the variety of English that a number of African Americans speak, may be one contributor to these differences. The effect of dialect may be indirect, in that AAVE may be evaluated negatively by schools and teachers. Alternatively, or in addition, certain characteristics of AAVE may directly affect reading and spelling. The present results show that at least one phonological characteristic of AAVE influences spelling even in adults. This conclusion differs from that of previous studies, which have found spelling errors related to AAVE phonology to be uncommon beyond the early school grades (Groff, 1978). The present results show that phonological as well as syntactic factors must be considered when one examines the effects of AAVE on literacy.

\section{REFERENCES}

Bailey, G., \& Thomas, E. (1998). Some aspects of African American vernacular English phonology. In S. S. Mufwene, J. R. Rickford, G. Bailey, \& J. Baugh (Eds.), African-American English: Structure, history, and use (pp. 85-109). London: Routledge.

BURT, J. S., \& FURY, M. B. (2000). Spelling in adults: The role of reading skills and experience. Reading \& Writing, 13, 1-30.

FRITH,U. (1985). Beneath the surface of developmental dyslexia. In K. E. Patterson, J. C. Marshall, \& M. Coltheart (Eds.), Surface dyslexia: Neuropsychological and cognitive studies of phonological reading (pp. 301-330). Hove, U.K.: Erlbaum.

Groff, P. (1978). Children's spelling of features of Black English. Research in the Teaching of English, 12, 21-28.

LABOv, W. (1995). Can reading failure be reversed? A linguistic approach to the question. In V. Gadsden \& D. Wagner (Eds.), Literacy among African-American youth (pp. 39-68). Cresskill, NJ: Hampton.

NATIONAL CENTER FOR EDUCATION STATISTICS(2002). The condition of education 2002. Retrieved September 30, 2002 from http://nces.ed.gov/ programs/coe/.

Pennington, B. F., Lefly, D. L., Van Orden, G. C., Bookman, M. O., \& SMITH, S. D. (1987). Is phonology bypassed in normal or dyslexic development? Annals of Dyslexia, 37, 62-89.

READ, C. (1975). Children's categorization of speech sounds in English (NCTE Research Report No. 17). Urbana, IL: National Council of Teachers of English.

READ, C. (1986). Children's creative spelling. London: Routledge \& Kegan Paul.

TREIMAN, R. (1993). Beginning to spell: A study offirst-grade children. New York: Oxford University Press.

TREIMAN, R., \& BARRY, C. (2000). Dialect and authography: Some differences between American and British spellers. Journal of Experimental Psychology: Learning, Memory, \& Cognition, 26, 1423-1430.

TREIMAN, R., CASSAR, M., \& ZUKOWSKI, A. (1994). What types of linguistic information do children use in spelling? The case of flaps. Child Development, 65, 1310-1329.

Treiman, R., Goswami, U., Tincoff, R., \& LeEvers, H. (1997). Effects of dialect on American and British children's spelling. Child Development, 68, 229-245.

Treiman, R., Kessler, B., \& BICK, S. (2002). Context sensitivity in the spelling of English vowels. Journal of Memory \& Language, 47, 448468.

Trowbridge, G. (2002, January 14). Racial divide widest in U.S. Detroit News. Retrieved September 4, 2002, from http://detnews.com.

UPTON, J. (2002, January 21). Segregated schools hurt students' bid for success. Detroit News. Retrieved September 4, 2002, from http:// detnews.com.

Zeno, S. M., Ivenz, S. H., Millard, R. T., \& Duvvuri, R. (1995).Educator's word frequency guide. Brewster, NY: Touchstone Applied Science Associates.

\section{NOTE}

1. Key to phonetic symbols: // as in roe, /d/ as in doe, /t/ as in toe.

\section{APPENDIX}

Final /d/, more frequent: arid, fluid, haggard, mallard, placid, rigid, sacred, steward, valid, vivid.

Final /d/, less frequent:fetid, lanyard, livid, lucid, putrid, rabid, rancid, sordid, squalid, tepid.

Final /t/, more frequent: abbot, ballot, exhibit, granite, hermit, inherit, portrait, scarlet, summit, thicket.

Final /t/, less frequent: agate, braggart, claret, gamut, respite, rivet, spigot, spinet, tacit, tenet. 